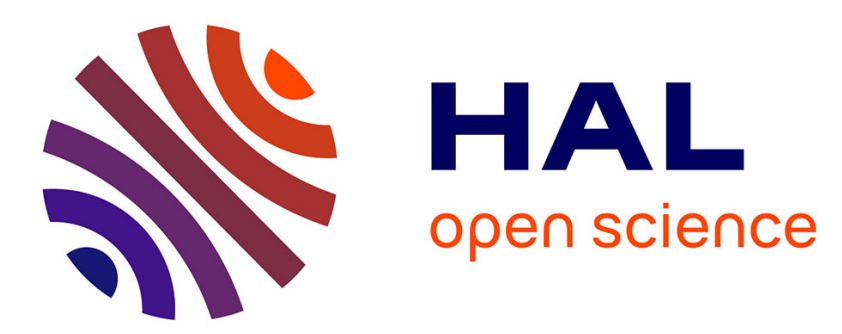

\title{
On the actual anode area that contributes to the current density produced by electroactive biofilms
}

Alessandro Carmona Martinez, Rémy Lacroix, Eric Trably, Serge da Silva, Nicolas Bernet

\section{- To cite this version:}

Alessandro Carmona Martinez, Rémy Lacroix, Eric Trably, Serge da Silva, Nicolas Bernet. On the actual anode area that contributes to the current density produced by electroactive biofilms. Electrochimica Acta, 2018, 259, pp.395-401. 10.1016/j.electacta.2017.10.200 . hal-02626318

\section{HAL Id: hal-02626318 \\ https://hal.inrae.fr/hal-02626318}

Submitted on 26 May 2020

HAL is a multi-disciplinary open access archive for the deposit and dissemination of scientific research documents, whether they are published or not. The documents may come from teaching and research institutions in France or abroad, or from public or private research centers.
L'archive ouverte pluridisciplinaire HAL, est destinée au dépôt et à la diffusion de documents scientifiques de niveau recherche, publiés ou non, émanant des établissements d'enseignement et de recherche français ou étrangers, des laboratoires publics ou privés. 


\section{Accepted Manuscript}

On the actual anode area that contributes to the current density produced by electroactive biofilms

Alessandro A. Carmona-Martínez, Rémy Lacroix, Eric Trably, Serge Da Silva, Nicolas Bernet

PII: S0013-4686(17)32346-0

DOI: 10.1016/j.electacta.2017.10.200

Reference: $\quad$ EA 30586

To appear in: Electrochimica Acta

Received Date: 11 August 2017

Revised Date: 18 October 2017

Accepted Date: 31 October 2017

Please cite this article as: A.A. Carmona-Martínez, Ré. Lacroix, E. Trably, S. Da Silva, N. Bernet, On the actual anode area that contributes to the current density produced by electroactive biofilms, Electrochimica Acta (2017), doi: 10.1016/j.electacta.2017.10.200.

This is a PDF file of an unedited manuscript that has been accepted for publication. As a service to our customers we are providing this early version of the manuscript. The manuscript will undergo copyediting, typesetting, and review of the resulting proof before it is published in its final form. Please note that during the production process errors may be discovered which could affect the content, and all legal disclaimers that apply to the journal pertain. 
Graphical abstract

On the consensus of the anode area that contributes to microbial current via:

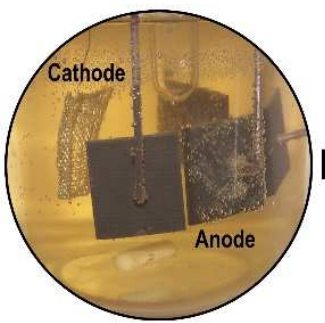

Reactor

Multi-electrode arrangement

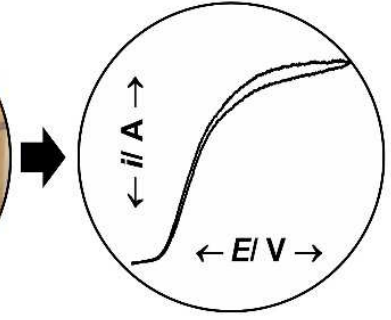

Electrochemistry Cyclic voltammetry

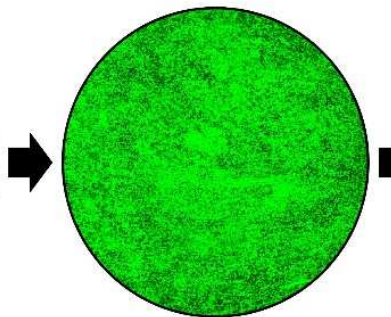

Microscopy Confocal laser scanning microscopy

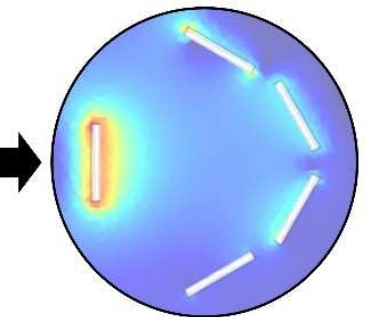

Modelling COMSOL Multiphysics 


\title{
On the actual anode area that contributes to the current density produced by electroactive biofilms
}

\author{
Alessandro A. Carmona-Martínez ${ }^{\mathrm{a}, \mathrm{c}}$ Rémy Lacroix $^{\mathrm{b}}$, Eric Trably ${ }^{\mathrm{a}}$, Serge Da Silva ${ }^{\mathrm{b}}$ and Nicolas Bernet ${ }^{\mathrm{a},{ }^{*}}$ \\ ${ }^{a}$ LBE, INRA, 102, Avenue des Etangs, Narbonne, 11100, France \\ b6T-MIC Ingénieries, ZI de VIC les Graves, 9, Rue du Developpement, 31320 Castanet Tolosan, France \\ 'Present adress: IMDEA Water Institute, Technological Park of the University of Alcalá, Alcalá de Henares, Spain \\ *Corresponding author: N. Bernet, LBE, INRA, 102 Avenue des Etangs, Narbonne, 11100, France, E-mail: \\ nicolas.bernet@inra.fr; T: +33(0)4 68425174
}

\section{Abstract}

Even with an increasing interest in scaling-up Microbial Electrochemical Technologies (MET), it is still common to focus on their "fundamentals". An important example is the production of current density $\left(j_{\max }\right)$ by microbial anodes in a three-electrode arrangement (3EA) configuration, e.g.: a graphite plate of well-defined projected (or geometric) surface area (PSA) and a cathode, both parallel to each other.

With such type of anode within a 3EA configuration, $j_{\text {max }}$ 's calculation is expected to be straightforward. Nonetheless, certain issues prevail. Occasionally, $j_{\max }$ is wrongly overestimated neglecting the surface of the anode that does not directly face the cathode.

Here, grown biofilms of the novel electroactive bacterium Geoalkalibacter subterraneus showed that the actual area of anode that contributes to $j_{\max }$ is the total PSA (or apparent geometric area) immersed in the electrolyte available to form a biofilm regardless the side of the anode that faced or opposed the cathode even in a medium with low conductivity such as urban wastewater, a niche of application for METs.

For the sake of normalization, researchers (and especially a "freshman" microbial electrochemist) are encouraged to: A) use the total PSA (or apparent geometric area) immersed in the electrolyte to calculate $j_{\max }$ or B) to cover edges and faces hidden of the anode with an electrical insulator to allow the flow of current on the side of the anode that directly faces the cathode prior calculation of $j_{\max }$. This normalization can be conducted when the main goal is to quantify (and thus properly report) $j_{\max }$ produced when using (e.g.): a novel i) electroactive bacterium, ii) electrode material or iii) reactor design.

Keywords: Electroactive biofilm • Geoalkalibacter subterraneus $・$ COMSOL Multiphysics ${ }^{\circledR} \bullet$ Electrode surface area $\bullet$ Microbial electrochemical technologies $\bullet$ Current density 


\section{Introduction}

Microbial Electrochemical Technologies (METs) take advantage of the electron transfer (ET) interactions occurring between electroactive bacteria (EAB) and electrode materials [1]. The use of these interactions impacts several rapid evolving technological fields ranging from the treatment of wastewater by the integration of METs into conventional treatment technologies [2], via the desalination of brackish water in microbial desalination cells [3], to the production of value-added molecules such as acetate from $\mathrm{CO}_{2}$ via microbial electrosynthesis [4].

Although several parameters are used to evaluate the performance of METs, such as the product yield or the coulombic efficiency, the calculation of the maximum current density $\left(j_{\max }\right)$ per projected (or apparent geometric) surface area (PSA) of anode material is among one of the most widely accepted parameters [5]. Despite the efforts to standardize the calculation of $j_{\max }$ to use the reported value for comparison among different studies, certain issues prevail regarding its proper calculation.

In three-electrode arrangement (3EA) experimental set-ups where a two-side planar anode (hereafter WE from "working electrode") is used in parallel to a cathode (henceforth CE from "counter electrode"), $j_{\max }$ is occasionally calculated neglecting the surface of the WE that does not directly face the CE [6]. This causes $j_{\max }$ to be wrongly overestimated, which in turn prohibits an objective comparison of results among studies.

When considering for example the case of a WE with dimensions of $2.5 \times 2.5 \times 0.25 \mathrm{~cm}$, some might use only the side of the WE that faces the CE to calculate $j_{\max }$ (i.e.: $6.25 \mathrm{~cm}^{2}$ ). However, in multiple experiments it is usually observed that the biofilm grows on all the immersed anode material which is in contact with the electrolyte (i.e. both electrode sides plus edges: $15.00 \mathrm{~cm}^{2}$, see Fig. A7 in Appendix A). Depending on the methodology used to calculate the surface area, $j_{\max }$ can therefore vary by a factor of 2.4 .

This overestimation might be due to the direct extrapolation of the information extracted from strictly electrochemical electrode processes' books. Such information is usually employed for the interpretation of microbial electron transfer mechanisms between electrodes and EAB that might be governed by completely different phenomena. As an example of this, it is reported in text books of fundamental electrochemistry that $j_{\max }$ strongly depends on the WE's proximity to the CE [7]. Thus, it is usually assumed that the current produced on the side of the WE that directly faces the $\mathrm{CE}$ will be significantly higher than the current produced on the back side of the WE that does not directly faces the CE [8] (please see Fig. A1 in Appendix A).

This manuscript proposes a consensus on the actual total PSA of anode that contributes to $j_{\max }$. Experiments were carried out with biofilms of the novel EAB Geoalkalibacter subterraneus and subjected to a multi-approach analysis with techniques that span from electrochemistry via microscopy to modelling. This is not an attempt to evaluate the overall performance of a bioelectrochemical device by its produced anodic current density alone as would be typical for MFC research. 


\section{Experimental}

\subsection{Overall experimental strategy}

A three-electrode arrangement was used (Fig. 1A). Four graphite plate anodes (WE) faced a single platinium-iridium cathode (CE). In the middle of the reactor a SCE reference electrode (RE) was placed. While WE1, WE2 and WE3 were chronoamperometrically (CA) and individually controlled at $+200 \mathrm{mV}$ vs. SCE, WE4 was not. A N-Stat (N) configuration was used, as similarly described by [9]. The N-Stat configuration allowed each WE to be connected to a separate potentiostat channel sharing the same RE and CE according to BioLogic's connection mode protocol. In the N-Stat configuration, the multi-channel potentiostat individually controls each anode with respect to a single RE.

On all WEs the growth of pure culture anodic biofilms of the novel EAB Geoalkalibacter subterraneus (henceforth Glk. subterraneus [10]) was followed by Confocal laser scanning microscopy (CLSM). Biofilm growth on anodes was allowed (green "tick" symbol in Fig. 1A) or limited by an electrical insulator (red "cross" symbol in Fig. 1A).

-Please insert Figure 1 here-

\subsection{Maintenance and growth of Geoalkalibacter subterraneus}

The growth and maintenance of Glk. subterraneus was carried out exactly as previously detailed elsewhere [10]. Glk. subterraneus was chosen here as a model EAB due to its shared similar electrochemical characteristics with the extensively well characterized EAB Geobater sulfurreducens in terms of its $j_{\max }$ and its electron transfer mechanism [11].

All chemicals were of analytical or biochemical grade and were purchased from SigmaAldrich and Merck. All media preparations were adjusted to $\mathrm{pH} 7$, vigorously flushed with $\mathrm{N}_{2}$ gas (purity $\geq 99.9999$, Linde France S.A.) for at least 30 min using a commercial air stone (or aquarium bubbler) and then autoclaved $\left(121^{\circ} \mathrm{C}\right.$ for $\left.20 \mathrm{~min}\right)$.

Sterile growth medium FRR was used for routinely culture maintenance and contained (per L): $17.0 \mathrm{~g}$ of NaCl, $4.50 \mathrm{~g}$ of $\mathrm{MgCl}_{2} \cdot 6 \mathrm{H}_{2} \mathrm{O}, 0.35 \mathrm{~g}$ of $\mathrm{CaCl}_{2} \cdot 2 \mathrm{H}_{2} \mathrm{O}, 1.00 \mathrm{~g}$ of $\mathrm{NH}_{4} \mathrm{Cl}, 0.08 \mathrm{~g}$ $\mathrm{KH}_{2} \mathrm{PO}_{4}, 3.50 \mathrm{~g}$ of $\mathrm{NaHCO}_{3}, 3.00 \mathrm{~g}$ of Yeast extract, $1 \mathrm{~mL}$ of trace element solution, $1 \mathrm{~mL}$ of selenite-tungstate solution and $1.00 \mathrm{~g}$ of $\mathrm{CH} 3 \mathrm{COONa}$ as electron donor.

\subsection{Electrode preparation and Bioelectrochemical set-up}

Preparation of electrodes and bioelectrochemical reactors was exactly conducted in agreement to a procedure reported elsewhere [10]. In brief: working electrodes were $2.5 \mathrm{~cm} \mathrm{x} 2.5 \mathrm{~cm} \mathrm{x}$ $0.25 \mathrm{~cm}$ planar graphite plates (C000440/15, Goodfellow SARL, 229 Rue Solférino, F-59000 Lille, France) screwed onto $2 \mathrm{~mm}$ diameter, $15 \mathrm{~cm}$ long titanium rods (TI007910/13, Goodfellow) that ensured electrical connection. Planar graphite electrodes were used as delivered by the provider. Counter electrodes were $90 \%$ Platinum-10\% Iridium grids joint by heating in a blue flame with a $0.5 \mathrm{~mm}$ diameter, $15 \mathrm{~cm}$ long $90 \%$ Platinum- $10 \%$ Iridium rod (Heraeus PSP S.A.S., Contact Materials Division, 526, Route des Gorges du Sierroz, 73100 Grésy-sur-Aix France). If not stated otherwise, all potentials provided in this manuscript refer 
to the Saturated Calomel reference Electrode (SCE) $(\mathrm{KCl} 3.0 \mathrm{M},+240 \mathrm{mV}$ vs. SHE, Materials Mates, La Guilletière 38700 Sarcenas, France).

To determine the contribution on $j_{\max }$ by both sides of a planar WE as part of the electrochemical set-up, four WEs were placed in the same electrochemical reactor facing a CE (Fig. 1A). However, not all the surface of the WE was available for the EAB to form a biofilm. To accomplish this, one side of the WE material was electrically insulated with a commercial seal (Siljoint, Bardahl ${ }^{\circledR}$ ) to make the covered WE's surface inaccessible for the EAB. Furthermore, to assure comparability and reproducibility all four WEs were simultaneously measured in one electrochemical reactor.

\subsection{Current density (j) calculation}

Current is calculated throughout this manuscript as i) per projected surface area $\left(j_{P S A}\right)$, which takes into account the absolute current $\left(i_{\text {absolute }}\right)$ divided by the projected surface area (PSA), an adequate calculation for compact and smooth electrodes with low degree of surface imperfections, such as the planar graphite plate electrodes used here, since they have a very well defined geometric surface area [12]. The mathematical modelling was conducted taking into account $j_{P S A}$. Maximum current density $\left(j_{\max }\right)$ refers to the maximum value extracted from the Chronoamperometric curve only.

Additionally, for sake of completeness current is also reported in Fig. 2 as ii) absolute current $\left(i_{\text {absolute }}\right)$, which is the current without taking into account the available surface area of anodic electrode material; and iii) current density as per electrochemically active surface area $\left(j_{E A S A}\right)$, that is based on the obtained charge by acetate oxidation during Chronoamperometry (i.e., integrated current over time). In an attempt to normalize the current to the real surface area of electrode available for the EAB to form a biofilm the electrochemically active surface area (EASA) was calculated as previously reported from the Anson equation [12]:

\section{$\mathrm{Q}_{\mathrm{d}}=2 \mathrm{nFEASA} \mathrm{C} \mathrm{D}{ }^{1 / 2} \pi^{1 / 2} \mathrm{t}^{1 / 2} \quad$ (Equation 1)}

Where $\mathrm{Q}_{\mathrm{d}}$ is the charge (C), i.e., current integrated over time from the Chronoamperometric curve; $\mathrm{n}$ the number of electrons transferred ( $8 \mathrm{~mol} \mathrm{e} / \mathrm{mol}$ acetate); $\mathrm{F}$ is the Faraday constant $(96485 \mathrm{C} / \mathrm{mol} \mathrm{e})$; EASA is the electrochemically active surface area $\left(\mathrm{cm}^{2}\right) ; \mathrm{C}$ is the concentration of the substrate $\left(1 \times 10^{-5} \mathrm{~mol}\right.$ acetate $\left./ \mathrm{ml}\right)$; D the diffusion coefficient of the substrate $\left(1.21 \times 10^{-5} \mathrm{~cm}^{2} / \mathrm{s}\right)$; and $\mathrm{t}$ is time (s). EASA was later used to calculate the current density with respect to the electrochemically active surface area and plotted in Figure $2 \mathrm{C}$. The Excel tool used for the calculation of EASA is provided as supplementary information in Appendix B.

\subsection{Cyclic voltammetry data and its processing}

Cyclic voltammetry (CV) of Glk. subterraneus biofilms was carried out under bioelectrocatalytic substrate consumption (the so-called "turnover conditions"). Chronoamperometric (CA) maximum current densities $\left(j_{\max }\right)$ of established microbial biofilms were calculated considering the total PSA immersed in the electrolyte and due to the presence of visible apparent reddish biofilms that covered all the electrode. Here all data are based on 
experiments of at least two independent biofilm replicates [5] and standard deviations are presented throughout the manuscript.

\subsection{Confocal laser scanning microscopy (CLSM) to measure biofilm electrode coverage and thickness}

Glk. subterraneus biofilms grown on WEs were examined by CLSM after staining with nucleic acid-specific fluorochromes exactly as reported elsewhere [10]. Whole electrodes were stained using the LIVE/ DEADs BacLightt Bacterial Viability Kit (Invitrogen) and confocal images of electroactive biofilms were acquired with a confocal laser scanning system (Leica TCS SP2, Leica Microsystems, Wetzlar, Germany).

\subsection{Modelling of the current density distribution on the electrode surface with COMSOL Multiphysics ${ }^{\circledR}$}

This type of exemplary modelling approach is more frequently employed to the study of strictly chemical electrode processes and very rarely employed for the study of the interactions of EAB embed within biofilms and electrode materials in METs [13-15]. Notwithstanding, the current density produced at each potentiostatically controlled electrode was later modeled with the software COMSOL Multiphysics ${ }^{\circledR}$ in an attempt to graphically illustrate the total PSA contribution on the current density production in METs.

To conduct the modelling, in COMSOL Multiphysics ${ }^{\circledR}$ the following parameters were introduced: A) Reactor geometry; B) Calculated conductivity for the electrolyte used; C) Polynomial equations for the anodic kinetic reactions; and D) Polynomial equations for the cathodic kinetic reactions.

It is worth noticing that the experiments carried out were originally focused on the anode performance. The potential of the electrode against the counter electrode has therefore not been measured during chronoamperometry and cyclic voltammetry. The value of the cell voltage used in modelling was thus adjusted to $1.1 \mathrm{~V}$ to reproduce the results experimentally observed.

\subsubsection{Reactor geometry definition in COMSOL Multiphysics ${ }^{\circledR}$}

A cylindrical electrochemical reactor as the one shown in Fig. A2 and Fig. A3 was used in the experiments and its dimensions were used in COMSOL Multiphysics ${ }^{\circledR}$. Its diameter was 10 $\mathrm{cm}$ with a height of $6 \mathrm{~cm}$ (working volume of $500 \mathrm{ml}$, i.e.: filled with microbiological medium for bacteriological growth). As depicted in Section 2.3, four graphite plates were used as working electrodes. The reference electrode was place right in the center of the reactor at a height that did not interfere with the distribution of current and potential. The relative position of all electrodes is depicted in Fig. 1, A3 and A4 (see Appendix B).

\subsubsection{Microbiological medium conductivity}

With the microbiological medium described in Section 2.2 and the information presented in Table 1 a conductivity of $5.0 \mathrm{~S} / \mathrm{m}$ at $25^{\circ} \mathrm{C}$ was calculated. This value has been introduced into COMSOL Multiphysics ${ }^{\circledR}$ and a simulation has been accordingly conducted. Additionally, a 
simulation at a conductivity value much lower of $0.1 \mathrm{~S} / \mathrm{m}$ was conducted since this conductivity value is the one usually ascribed to domestic wastewater. At his point, it is good to keep in mind that the current applications of METs are thought to be focused on the treatment of domestic wastewater.

Table 1. Electrolyte conductivity calculation of the growth medium used in this study.

\begin{tabular}{|c|c|c|c|c|c|c|c|}
\hline Compound "i" & {$[\mathbf{i}] /$} & {$[\mathrm{i}] /$} & [Cation]/ & [Anion] / & $\lambda_{+} /$ & $\lambda .1$ & Conductivity/ \\
\hline & $\mathrm{g} \mathrm{L}^{-1}$ & $\operatorname{mmol~} \mathrm{L}^{-1}$ & $\mathrm{mmol} \mathrm{L}^{-1}$ & $\operatorname{mmol~L}^{-1}$ & $10^{-4} \mathrm{~m}^{2} \mathrm{~S} \mathrm{~mol}{ }^{-1}$ & $10^{-4} \mathrm{~m}^{2} \mathrm{~S} \mathrm{~mol}^{-1}$ & $S \mathbf{~ m}^{-1}$ \\
\hline $\mathrm{NaCl}$ & 17.0 & 290.9 & {$\left[\mathrm{Na}^{+}\right]=290.9$} & {$\left[\mathrm{Cl}^{-}\right]=290.9$} & $\mathrm{Na}^{+}: 50.1$ & $\mathrm{Cl}^{-}: 76.3$ & 3.7 \\
\hline $\mathrm{MgCl}_{2} \bullet 6 \mathrm{H}_{2} \mathrm{O}$ & 4.5 & 22.2 & {$\left[\mathrm{Mg}^{2+}\right]=22.2$} & {$\left[\mathrm{Cl}^{-}\right]=44.4$} & $1 / 2 \mathrm{Mg}^{2+}: 53.0$ & $\mathrm{Cl}^{-}: 76.3$ & 0.6 \\
\hline $\mathrm{NaHCO}_{3}$ & 3.5 & 41.7 & {$\left[\mathrm{Na}^{+}\right]=41.7$} & {$\left[\mathrm{HCO}_{3}{ }^{-}\right]=41.7$} & $\mathrm{Na}^{+}: 50.1$ & $\mathrm{HCO}_{3}{ }^{-}: 44.5$ & 0.4 \\
\hline $\mathrm{CH}_{3} \mathrm{COONa}$ & 1.0 & 12.2 & {$\left[\mathrm{Na}^{+}\right]=12.2$} & {$\left[\mathrm{CH}_{3} \mathrm{COO}^{-}\right]=12.2$} & $\mathrm{Na}^{+}: 50.1$ & $\mathrm{CH}_{3} \mathrm{COO}^{-}: 41.0$ & 0.1 \\
\hline
\end{tabular}

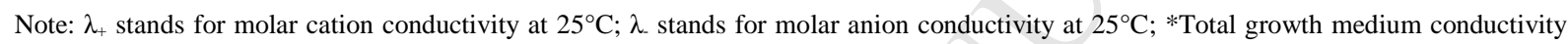
due to " $\mathrm{i}$ " compounds. Due to the high content of $\mathrm{NaCl}$ used in this medium preparation, it is evident that the conductivity of the medium it is independent of the rest of the additional compounds within the medium and mainly attributed to the $\mathrm{NaCl}$ content.

\subsubsection{Anodic reactions' kinetics}

Anodic kinetic curves were obtained during cyclic voltammetry (CV) under catalytic conditions (Fig. A5). Both forward and backward sigmodal-like signals were very similar. Thus, only the backward signal was adjusted to a polynomial fitting. CV shown that the three electrodes share similar kinetics. Independently of the orientation of the available electrode surface the current density obtained by each electrode was very similar as well (see Fig. 3A).

\subsubsection{Cathodic reaction's kinetics}

The kinetics of the electrolysis of water for hydrogen production at a scan rate of $1 \mathrm{mV} / \mathrm{s}$ on a $\mathrm{Pt} / \mathrm{Ir}$ counter electrode was experimentally measured in similar three-electrode arrangement set-up as the one previously described, i.e.: graphite working electrode, $\mathrm{Pt} / \mathrm{Ir}$ counter electrode and SCE reference electrode. The medium composition shown in Table 1 was used as electrolyte.

\section{Results and Discussion}

\subsection{Chronoamperometric current density of Glk. subterraneus biofilms}

In Fig. 2 current is shown as i) per projected surface area $\left(j_{P S A}\right)$, an adequate calculation for planar graphite plate electrodes with a very well defined geometric surface area. For sake of completeness current is also shown as ii) absolute current $\left(i_{\text {absolute }}\right)$, i.e., the current without taking into account the available surface; and iii) current density as per electrochemically active surface area $\left(j_{E A S A}\right)$, based on the obtained charge by acetate oxidation during Chronoamperometry. 
After inoculation with cells of Glk. subterraneus, the biofilm growth began and it was illustrated as an exponential-like current production trend as previously described for this particular EAB [10] (Fig. 2). Interestingly, the biofilm growth was very similar on all WEs as indicated by the chronoamperometric current production trend. No effect was observed in terms of current production among WE1, WE2 and WE3. The current density $j_{\max }$ was very closely similar for WE1, WE2 and WE3, with $2.60 \pm 0.01,2.66 \pm 0.07$ and $2.57 \pm 0.07 \mathrm{~A} / \mathrm{m}^{2}$, respectively. Although $j_{\text {max }}$ of WE2 was slightly higher with respect to WE1 and WE3, there was no significant difference between these three WEs.

During chronoamperometric measurements the actual area of anode that contributed to $j_{\max }$ was the total PSA (or apparent geometric area) immersed in the electrolyte regardless the side of the anode that faced the cathode.

\subsubsection{Accurate calculation of current density regarding the porosity of the material}

As described in the Experimental section, current density was calculated by two methods. The first one divides the absolute current $\left(i_{\text {absolute }}\right)$ by the geometric projected surface area $\left(j_{P S A}\right)$. The second one is an attempt to normalize the current to the real electrochemically active surface area of electrode available for the EAB to form a biofilm $\left(j_{E A S A}\right)$. In this work, graphite plate electrodes with a very well defined surface area were used. Nevertheless, when calculating $j_{E A S A}$ by the method suggested elsewhere it was observed, as expected, that the available electrochemically active surface area (EASA) was higher than the one geometrically calculated. Thus, $j_{E A S A}$ was lower than $j_{P S A}$ since the Anson equation (see equation 1) somehow provides an approximation of the real EASA available for the EAB to form a biofilm. It is worth noticing that EASA will always be higher than the geometric surface area consider in the calculation of $j_{P S A}$ due to the inherent complex distribution of the EASA at a microscopic level.

\section{-Please insert Figure 2 here-}

\subsection{Direct electron transfer mechanism (ETM)}

Cyclic voltammetry (CV) is one of the most employed electrochemical techniques in METs to study at some extent how EAB interact with the electrode material, either anodes or cathodes [16]. CV is used to decipher the electron transfer mechanism (ETM) by which electrons are transferred between $\mathrm{EAB}$ and electrodes [17]. Here, turnover CV (i.e., under bioelectrocatalytic substrate consumption conditions) was applied to analyse whether there was any difference in the ETM of microbial biofilms developed on different sides of the anode in METs.

Independent biofilms grown on WE1, WE2 and WE3 showed an indistinguishable sigmoidal shape from each other (Fig. 3A). Such shape is typical of EAB able to produce high currents and thick biofilms via a direct ETM [10]. The similarities in the ETM showed by all anodes imply that irrespective of the anode side available for biofilm growth, the same ETM is used at both sides of an anode that faces or opposes a cathode. In Fig. 3A a flat voltammogram indicates a typical control CV with no electroactive biofilm to illustrate that the sigmoidal CV shape is caused by the biofilm under catalytic "turnover conditions". 
When determining the formal potential $\left(E_{f}\right)$ of the ETM by calculating the first derivative of CVs (Fig. 3B), the $E_{f}$ observed for all tested WEs was $-474.99 \pm 1.29 \mathrm{mV}$ vs. SCE. Such low standard deviation confirmed that the EAB within biofilms used the same ETM. This is easily understood when taking into account that the same scan rate and the same biological conditions were assured for all WEs since all anodes were hosted within the same electrochemical reactor.

Cyclic voltammetric measurements thus confirm that the actual area of anode that contributed to the ETM was the total PSA (or apparent geometric area) immersed in the electrolyte regardless the anode side that faced the cathode.

-Please insert Figure 3 here-

\subsection{Homogeneous biofilm formation independently of the anode side orientation}

Together with the analysis of $j_{\max }$ and ETM on WE1, WE2 and WE3, a microscopic analysis with CLSM was performed on all anodes (including WE4) to determine any possible effect on biofilm formation and thickness due to the orientation of the anode.

Once again, no appreciable effect was observed whatever the orientation of the anode side with respect to the cathode. Biofilms on WE1, WE2 and WE3 were similarly covering the entire apparent available anode PSA (Fig. 4). With the LIVE/DEAD ${ }^{\circledR}$ kit, it was possible to see that WE1, WE2 and WE3 were homogeneously covered by metabolically active cells of Glk. subterraneus with similar thickness values of $75 \pm 7,66 \pm 26$ and $71 \pm 12 \mu \mathrm{m}$, for WE1, WE2 and WE3, respectively. CLSM analysis of biofilms not only confirmed a very uniform coverage of anodes at the microscopic level but also at the macroscopic perspective as previously observed by visual inspection of a reddish biofilm (see Fig. A2 in Appendix A).

WE4 was not potentiostatically controlled. Consistently, no significant biofilm formation was observed when using CLSM. The thickness value estimated for WE4 $(13 \pm 1 \mu \mathrm{m})$ suggests that the "few" bacterial cells observed by CLSM on the anode surface corresponded to an heterogeneous deposition of bacterial cells likely detached from the other potentiostatically controlled anodes (WE1, WE2 and WE3) on which Glk. subterraneus successfully formed an electroactive biofilm.

CLSM certified that the actual area of anode that was available for biofilm formation was the total PSA (or apparent geometric area) immersed in the electrolyte regardless the side of the anode that faced the cathode.

-Please insert Figure 4 here-

\subsection{Modelling of the current density distribution on anodes with COMSOL Multiphysics ${ }^{\circledR}$}

The current density produced at each potentiostatically controlled anode was later modeled with the software COMSOL Multiphysics ${ }^{\circledR}$ in an attempt to graphically illustrate the anode area contribution on the current density produced in METs (Fig. 5). It was clear that the anodic current densities are very similar on the available surface areas of each electrode independently whether the available surface of the anode faced or opposed the cathode. 
A common argument regarding the calculation of the current density per available surface area in METs is that at such high conductivity of $5.0 \mathrm{~S} / \mathrm{m}$ as the one used here all the available anode surface area will very likely contribute to the current density regardless the side of the anode that faced the cathode (see Table 1). Thus, a further simulation was conducted at the typical conductivity found in urban wastewater $(0.1 \mathrm{~S} / \mathrm{m})$.

It was observed that at $0.1 \mathrm{~S} / \mathrm{m}$, a decrease of the current density of about $16 \%$ can occur on all WEs when compared to the modelling at $5.0 \mathrm{~S} / \mathrm{m}$ (data not shown). Nonetheless, the current density of WE1, WE2 and WE3 is still independent of the orientation of the electrode surface with respect to the CE.

The conducted modelling approach with COMSOL Multiphysics ${ }^{\circledR}$ showed that the actual area of anode that contributes to $j_{\max }$ is the total PSA (or apparent geometric area) immersed in the electrolyte independently of the side of the anode that faces the cathode even in a medium with low conductivity such as urban wastewater, a common niche of application for METs.

\section{-Please insert Figure 5 here-}

\section{Conclusions}

The use of a combined approach of electrochemistry, microscopy and modelling for the analysis of electroactive biofilms formed by Glk. subterraneus allowed to determine the contribution of each anode side orientation on the current density produced in METs. The use of chronoamperometry showed that no effect was observed whatever the anode orientation (WE1, WE2 and WE3), since $j_{\max }$ was similar for all anodes potentiostatically controlled. Turnover cyclic voltammetry of anodes also indicated a common direct electron transfer mechanism that was confirmed after calculation of their shared formal potential from first derivative curves. The analysis of biofilms by confocal laser scanning microscopy showed, once again, no appreciable effect of the anode orientation side with respect to the cathode. Biofilms on WE1, WE2 and WE3 anodes covered the entire apparent available projected surface area with clearly similar thickness values ranging from 66 to $75 \mu \mathrm{m}$. A modelling approach supported the experimental observations by confirming that the current densities were very similar whatever the available anode side considered, i.e. anode side that faced or opposed the cathode. In conclusion and with a purpose of standardization of $j_{\max }$ assessment, certain areas of the anode (hidden edges or faces) with uncertain electrochemical activity should be covered with an electrical insulator to further consider only the flow of current on the side of the anode directly facing the cathode when for example the main goal of the study is to quantify the current density produced by a novel i) electroactive bacterium, ii) electrode material or iii) reactor design.

\section{Acknowledgements}

This research was financed by the French National Research Agency (ANR-09-BioE-10 DéfiH12). A.A.C.M gratefully acknowledges C. Pouzet at the Plateforme d'imagerie FR-AIB, TRI-Genotoul for technical assistance with CLSM.

\section{References}


[1] S. Patil, C. Hägerhäll, L. Gorton, Electron transfer mechanisms between microorganisms and electrodes in bioelectrochemical systems, Bioanalytical Reviews, 4 (2012) 159-192.

[2] A. Aguirre-Sierra, T. Bacchetti-De Gregoris, A. Berna, J.J. Salas, C. Aragon, A. Esteve-Nunez, Microbial electrochemical systems outperform fixed-bed biofilters in cleaning up urban wastewater, Environmental Science: Water Research \& Technology, 2 (2016) 984-993.

[3] Z. Borjas, A. Esteve-Núñez, J.M. Ortiz, Strategies for merging microbial fuel cell technologies in water desalination processes: Start-up protocol and desalination efficiency assessment, Journal of Power Sources, (2017).

[4] C.W. Marshall, E.V. LaBelle, H.D. May, Production of fuels and chemicals from waste by microbiomes, Current Opinion in Biotechnology, 24 (2013) 391-397.

[5] B.E. Logan, Essential Data and Techniques for Conducting Microbial Fuel Cell and other Types of Bioelectrochemical System Experiments, ChemSusChem, 5 (2012) 988-994.

[6] C. Dumas, R.g. Basseguy, A. Bergel, DSA to grow electrochemically active biofilms of Geobacter sulfurreducens, Electrochimica Acta, 53 (2008) 3200-3209.

[7] A.J. Bard, L.R. Faulkner, Electrochemical Instrumentation, Electrochemical Methods: Fundamentals and Applications, Wiley2000.

[8] D. Pletcher, Experimental electrochemistry, A First Course in Electrode Processes, Royal Society of Chemistry2009.

[9] C.I. Torres, R. Krajmalnik-Brown, P. Parameswaran, A.K. Marcus, G. Wanger, Y.A. Gorby, B.E. Rittmann, Selecting anode-respiring bacteria based on anode potential: Phylogenetic, electrochemical, and microscopic characterization, Environmental Science and Technology, 43 (2009) 9519-9524.

[10] A.A. Carmona-Martínez, M. Pierra, E. Trably, N. Bernet, High current density via direct electron transfer by the halophilic anode respiring bacterium Geoalkalibacter subterraneus, Physical Chemistry Chemical Physics, 15 (2013) 19699-19707.

[11] N.S. Malvankar, D.R. Lovley, Microbial nanowires for bioenergy applications, Current Opinion in Biotechnology, 27 (2014) 88-95.

[12] M. Sharma, S. Bajracharya, S. Gildemyn, S.A. Patil, Y. Alvarez-Gallego, D. Pant, K. Rabaey, X. Dominguez-Benetton, A critical revisit of the key parameters used to describe microbial electrochemical systems, Electrochimica Acta, (2014).

[13] C. Picioreanu, M.C.M. van Loosdrecht, T.P. Curtis, K. Scott, Model based evaluation of the effect of $\mathrm{pH}$ and electrode geometry on microbial fuel cell performance, Bioelectrochemistry, 78 (2010) 824.

[14] E. Dalak, Evaluation of Unified Numerical and Experimental Methods for Improving Microbial Electrochemical Technologies (MXCs), University of Toulouse III - Paul Sabatier, Toulouse, 2012, pp. 91.

[15] R. Lacroix, S.D. Silva, M.V. Gaig, R. Rousseau, M.-L. Delia, A. Bergel, Modelling potential/current distribution in microbial electrochemical systems shows how the optimal bioanode architecture depends on electrolyte conductivity, Physical Chemistry Chemical Physics, 16 (2014) 22892-22902.

[16] F. Harnisch, S. Freguia, A Basic Tutorial on Cyclic Voltammetry for the Investigation of Electroactive Microbial Biofilms, Chemistry - An Asian Journal, 7 (2012) 466-475.

[17] C.I. Torres, A.K. Marcus, H.S. Lee, P. Parameswaran, R. Krajmalnik-Brown, B.E. Rittmann, A kinetic perspective on extracellular electron transfer by anode-respiring bacteria, FEMS Microbiology Reviews, 34 (2010) 3-17. 
Figure captions:

Figure 1. (A) Photograph and (B) Top view of the electrode arrangement within the electrochemical reactor showing the relative orientation of the four anodes (WE1-4). The availability or electrical insulation of the anode surface is indicated by the green "tick" or red "cross" symbol, respectively. Anode WE4 was not potentiostatically controlled.

Figure 2. Chronoamperometric current production by biofilms grown on WE1, WE2 and WE3 anodes. A) Absolute current without dividing by the available surface area, B) Current density by geometric surface and C) Current density calculated by the real electrochemically active surface area. Thick and thin lines indicate duplicates of the same experimental condition conducted independently in chronological order. $\downarrow \mathrm{CV}$ : control cyclic voltammetry $(\mathrm{CV})$ without biofilm; t-CV $\uparrow$ : turnover-CV of biofilm under catalytically active acetate conversion; CLSM: stop of experiment and biofilm preparation for CLSM analysis. WE4 was not potentiostatically controlled. Thus, it is not depicted.

Figure 3. A) Turnover cyclic voltammetry (i.e.: under catalytically active acetate conversion) of mature biofilms grown on anodes WE1 (black), WE2 (blue) and WE3 (red) and $\mathrm{B}$ ) their respective first derivative curve. In A: flat $\mathrm{CV}$ indicates control $\mathrm{CV}$ without biofilm. WE4 was not potentiostatically controlled. Thus, it is not depicted.

Figure 4. CLSM maximum intensity projections of mature biofilms on anodes. It is shown that independently of the anode side available for biofilm formation its surface is uniformly covered by Glk. subterraneus cells. A projection of WE4 is shown to exemplify that no significant bacterial cell deposition occurred due to the non "potentiostaticallycontrolled" condition of this anode.

Figure 5. Modelling with COMSOL Multiphysics ${ }^{\circledR}$ of current density distribution on anodes. 
404 Figures:

405 Figure 1:
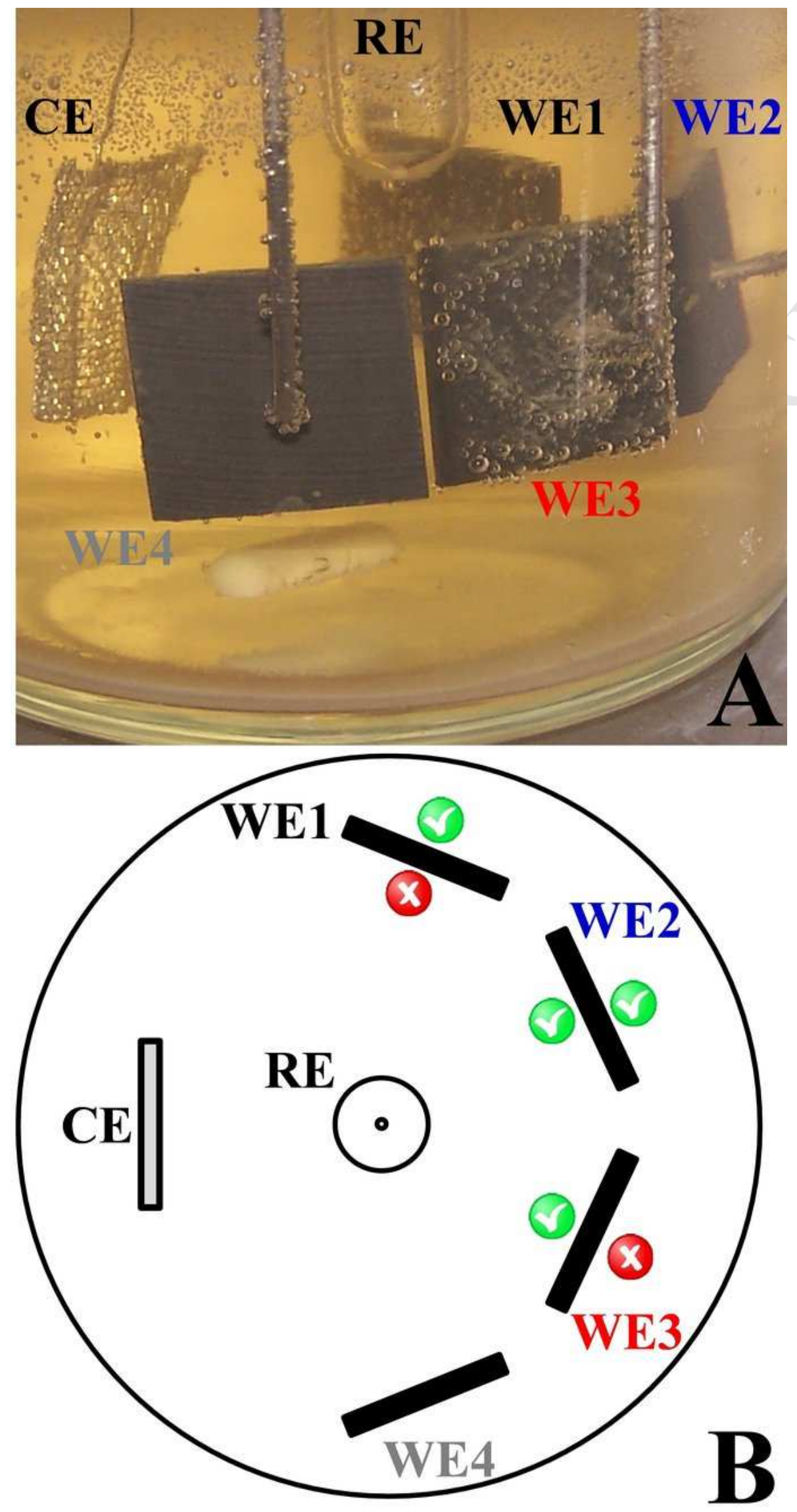
Figure 2:
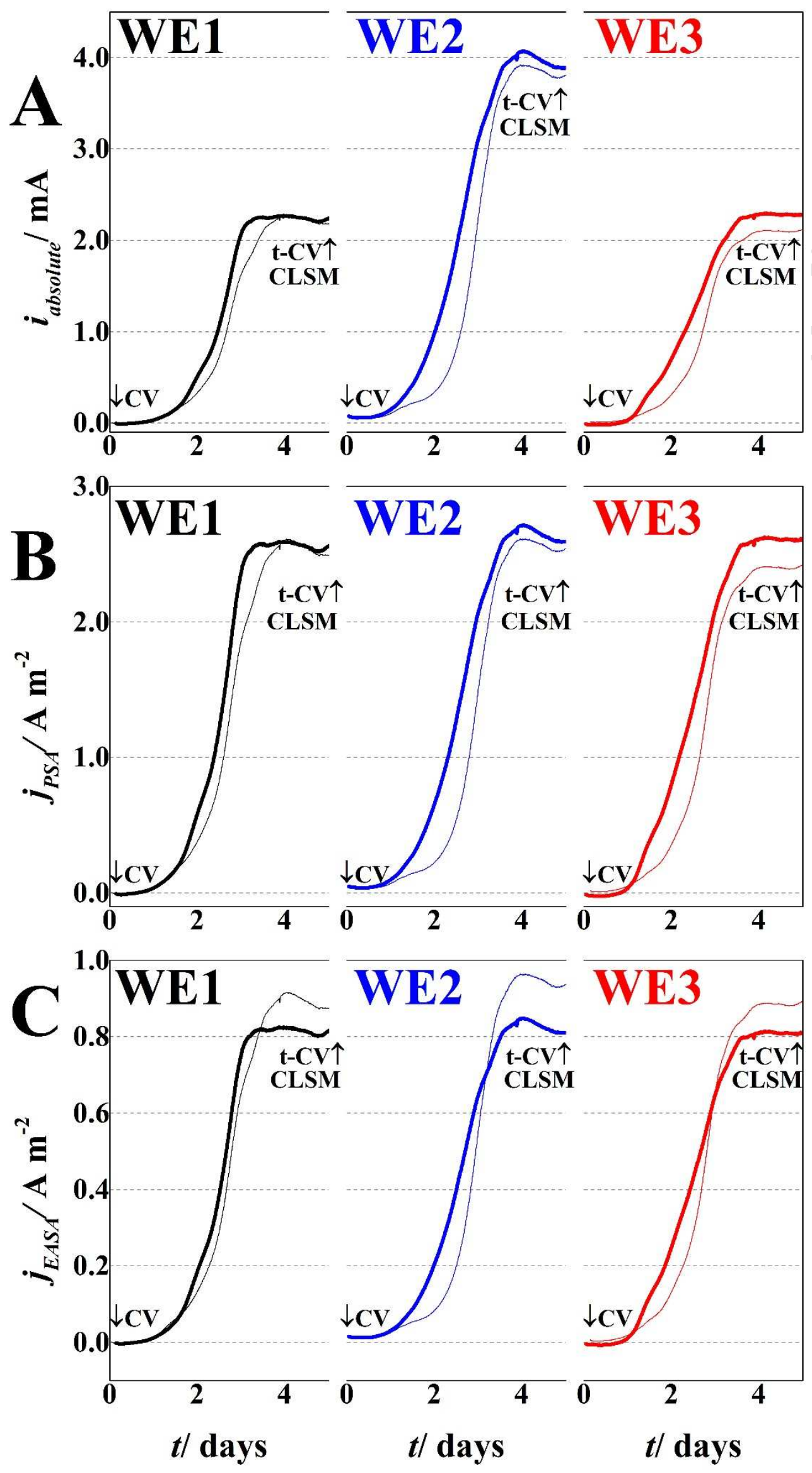
Figure 3:
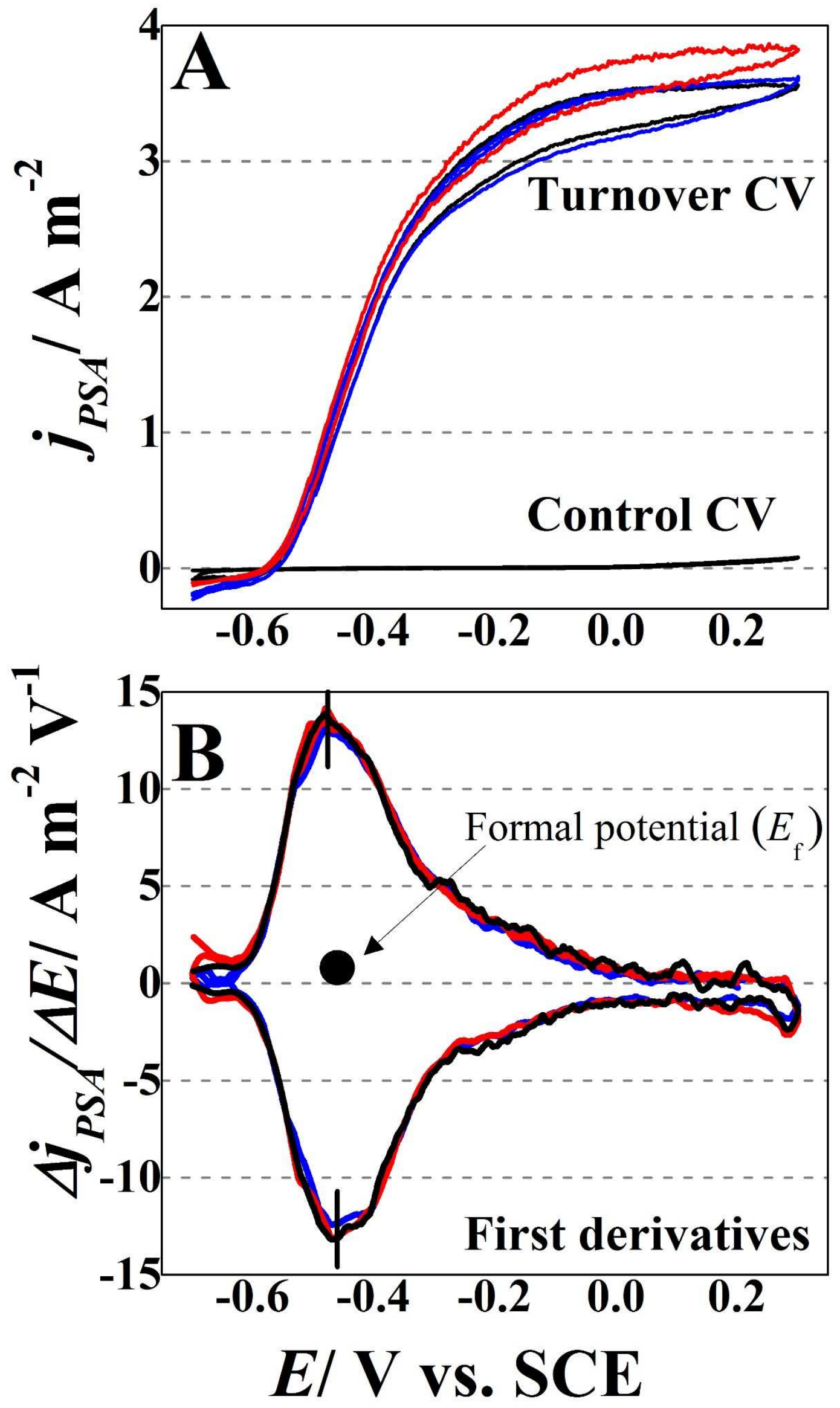
$411 \quad$ Figure 4:

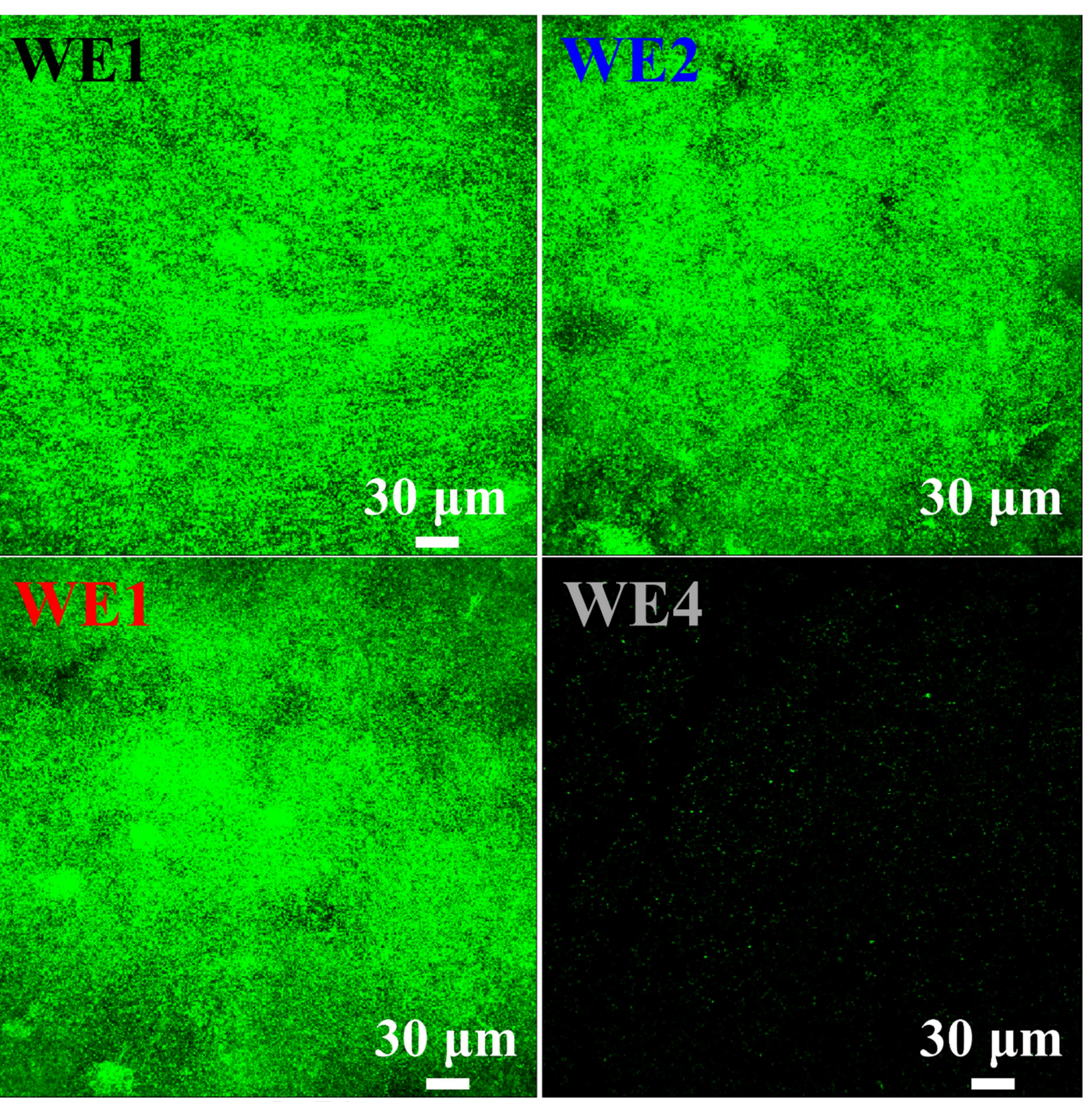

412

413 
414 Figure 5:

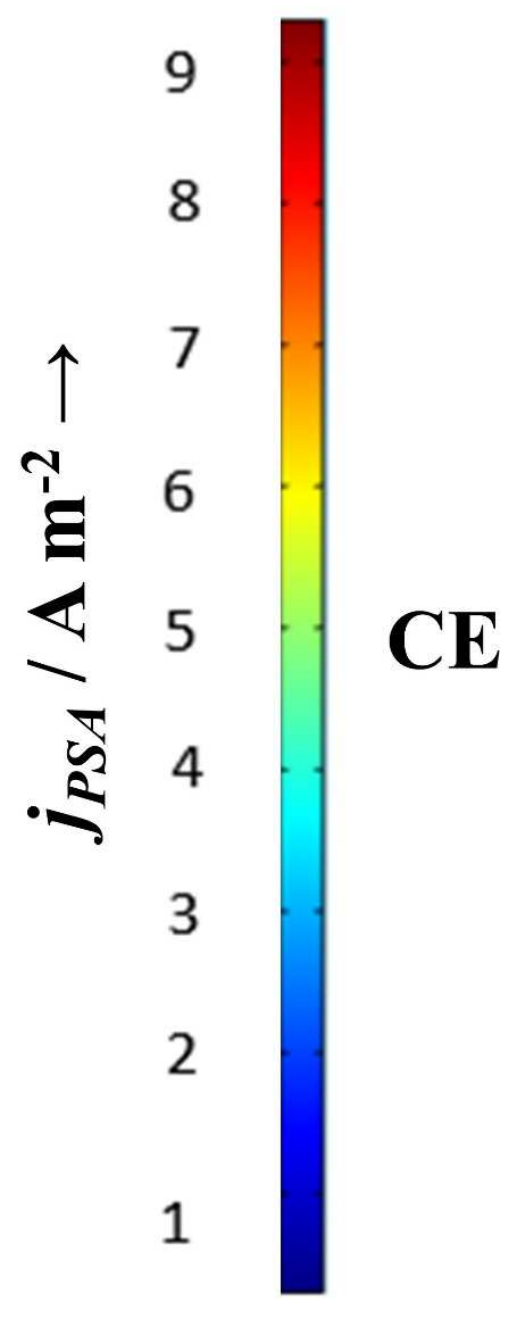

WE1

WE2

WE3

\section{WE4}

415 


\section{Highlights}

- Consensus on the anode area contributing to microbial current production is proposed.

- Electrochemistry and microscopy confirm the anode area actively producing current.

- Total immersed area in the electrolyte should be used to calculate current density.

- Sides hidden from cathode shall be electrically insulated to avoid overestimation. 